\title{
CRISPR/Cas9: a breakthrough in generating mouse models for endocrinologists
}

\author{
Suzy Markossian and Frédéric Flamant
}

Institut de Génomique Fonctionnelle de Lyon, Université de Lyon, CNRS, INRA, École Normale

Supérieure de Lyon, Lyon Cedex 07, France

Correspondence should be addressed

to F Flamant

Email

Frederic.Flamant@ens-lyon.fr

\begin{abstract}
CRISPR/Cas9 is a recent development in genome editing which is becoming an indispensable element of the genetic toolbox in mice. It provides outstanding possibilities for targeted modification of the genome, and is often extremely efficient. There are currently two main limitations to in ovo genome editing in mice: the first is mosaicism, which is frequent in founder mice. The second is the difficulty to evaluate the advent of off-target mutations, which often imposes to wait for germline transmission to ensure genetic segregation between wanted and unwanted genetic mutations. However rapid progresses are made, suggesting that these difficulties can be overcome in the near future.
\end{abstract}

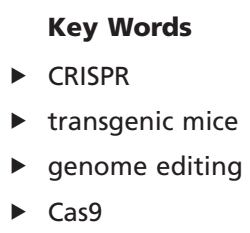

Journal of Molecular Endocrinology (2016) 57, R81-R92

\section{The CRISPR/Cas9 technology}

CRISPR/Cas9 genome editing technology is a genuine technological breakthrough. Based on an immune defense mechanism discovered in bacteria (Terns \& Terns 2011), the method was adapted and first used in mammalian cells in 2013 (Cong et al. 2013, Mali et al. $2013 b$ ). These initial studies opened a field of very intense investigation and technological development making genome editing very efficient in a number of animal species. The method also raises new hopes for human gene therapy (Xue et al. 2016).

As endocrinologists need animal models forc in vivo integrated studies and make an intensive use of genetic manipulations in mice to study physiology and pathology, the advent of CRISPR/Cas9 genome editing is expected to deeply impact the discipline. This review focuses on the achievements and potential of this technology in the field of mouse genetics and the general benefit that it should bring to research in endocrinology.

\section{Principle of CRISPR/Cas genome editing}

The recent history of mouse genetics is marked by sudden accelerations due to technological revolutions. The first such revolution was the opportunity to generate transgenic mice by DNA microinjection into fertilized oocytes. This sometimes leads to random DNA integration, meaning that neither the integration site nor the number of integrated copies is controlled (Palmiter \& Brinster 1985). The second revolution was the possibility to replace the process of random DNA integration by targeted integration, occurring if homologous recombination takes place between an exogenous DNA construct and the cognate genomic sequence. The occurrence of such homologous recombination events is not frequent. This strategy thus implies using embryonic stem (ES) cells, screening for homologous recombination event among a large number of cell clones, and then grafting the appropriate cells into recipient embryos. The chimeric mice born from the grafted embryos can then transmit the DNA modification through their germ line. This lengthy

Published by Bioscientifica Ltd 
process makes expression pattern more predictable and stable over generations. It also allows to generate knockout allele by disrupting endogenous gene (Capecchi 2005, Thomas \& Capecchi 1987). The third major progress was the advent of the Cre/loxP technology, which permits to generate recombination events only in cells expressing the Cre recombinase and thus restrict the consequences of mutation and transgene expression to selected tissues (Gu et al. 1994, Kuhn et al. 1995, Wilson \& Kola 2001). Generating somatic mutations in chosen tissues or cell types sometimes enable to avoid early lethality. Most importantly, for endocrinologists, Cre/loxP allows to uncouple the local consequences of a mutation and its systemic consequences, and provides a much deeper understanding of the gene functions (Davey \& MacLean 2006). All these methods are used to integrate reporter constructs, to tag endogenous protein, and most of all to generate gain-of-function or loss-of-function mutations. The technology is difficult to master and poorly efficient, and the creation of a new mouse strain remains a very time-consuming process. Despite these difficulties, the International Mouse Phenotype Consortium (http:// www.mousephenotype.org/) has been set to generate thousands of mouse models, mainly knockouts, which are now actively used in many laboratories. However, considering the degree of sophistication achieved in animal models that are cheaper and easier to breed, like Drosophila melanogaster, it is obvious that this systematic effort will never fulfill the growing need for new mouse models. So, even in mice, which have always been at the forefront of animal genetics, any new addition to the genetic toolbox is welcomed.

A promising development is genome editing, in which the genomic sequence is modified without necessarily inserting exogenous DNA. Genome editing was first performed using zinc finger nucleases (Pabo et al. 2001), and then transcriptional activator-like effector nucleases (TALENs) (Richter et al. 2016). Both endonucleases are modular proteins that can be engineered to fit a predefined sequence, by assembling the modules of coding sequences in an expression vector. They can thus recognize a unique genomic sequence and cut doublestranded DNA at a chosen locus. The presence of a doublestrand break then activates the cellular machinery for DNA repair which can proceed in two distinct ways, each of them enabling genome editing. The first possibility is repair by nonhomologous end joining (NHEJ), an errorprone mechanism that often produces small insertions and deletions (indels) at the DNA break. The second is homology-directed repair (HDR), in which the cell uses a template to repair the cut DNA, either the remaining intact allele or the exogenous DNA introduced in the cell together with the nuclease. Genome editing can modify the existing genes in a more subtle manner than classical transgenesis, as only few nucleotides are modified.

The CRISPR/Cas9 genome editing method (for CRISPR)/Cas9) is the last addition to the genetic toolbox. The most common version (Ran et al. 2013b) was developed from a bacterial system of adaptive immune defense against bacteriophages present in Streptococcus pyogenes. For this purpose, complete synthesis of the nuclease reading frame was completed, optimizing translation in mammalian cells. Importantly, and unlike the other nucleases used for genome editing, Cas9 uses a short RNA as guide to target a genomic sequence (Fig. 1). This single-guide RNA (sgRNA) of 100 nucleotides (nt) long. Its $5^{\prime}$ end (17-20 nt) is chosen to be complementary to the target DNA strand, on which it anneals. If the 17-20 nt DNA target sequence is immediately followed by the so-called protospacer adjacent motif (PAM) (e.g., 5'-NGG-3'), Cas9 cleaves the target on both strands. The double-strand break, located $3 \mathrm{nt}$ upstream to the PAM, will be repaired by either NHEJ or HDR. NHEJ errors generate random indels, whereas HDR can be used to copy precise modifications present in an exogenous DNA template. The key innovation is that the specificity of Cas9 for a genomic target stems from this sgRNA:DNA complementarity and not from protein structure, which does not have to be modified. Therefore, editing a chosen genomic sequence avoids laborious protein design, and simply involves the synthesis of a short nucleotide sequence to modify the $5^{\prime}$ end of the sgRNA (Table 1 ). The method is therefore straightforward, versatile, easily multiplexed, and, most of the time, extremely efficient. In our opinion, it already outperforms all the other methods of genetic modification. Although we only review its use to modify the mouse genome, it seems to be equally efficient in cultured cells and in all the plant and animal species where it has been tested (Yu et al. 2013, Xing et al. 2014, Zhu et al. 2014, Shen et al. 2014b, Shi et al. 2015).

\section{Possible use of CRISPR/Cas9}

The potentiality of CRISPR/Cas9 seems unlimited, and a number of possibilities have already been explored (Fig. 2). Excellent reviews have been published, providing step-by-step procedures and detailed protocols (Ran et al. 2013b, Yang et al. 2014), and DNA constructs for Cas9 expression are freely available (http://addgene.org/). The simplest application of CRISPR/Cas9 is to generate

Published by Bioscientifica Ltd 


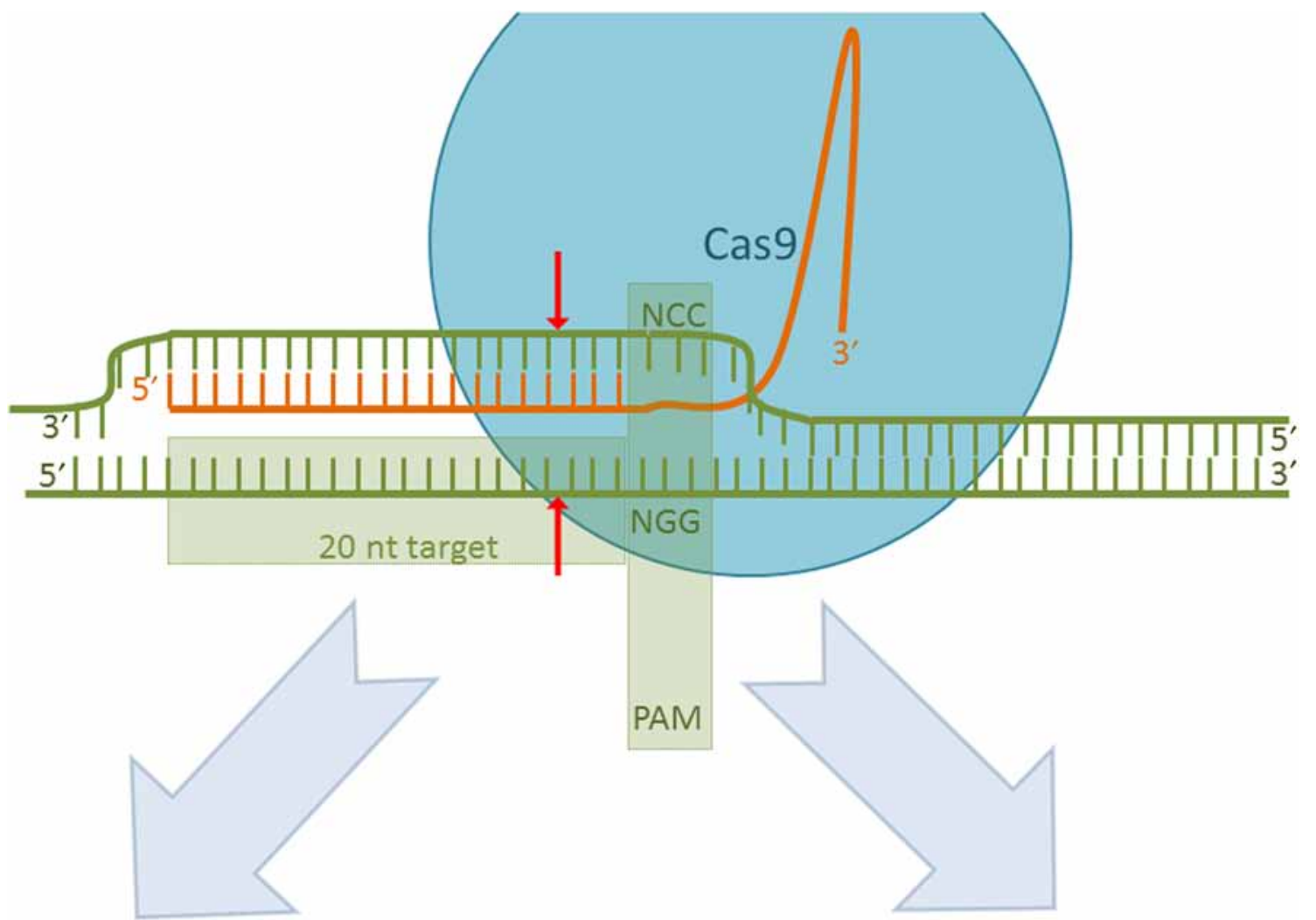

Non-homologous end pair joining

Homology directed repair

\section{Figure 1}

CRISPR/Cas9 genome editing principle. Genome editing relies on the ability of the RNA-guided Cas9 nuclease to cleave both strands of DNA. About 17-20 nt of genomic DNA, termed a protospacer, are targeted. This DNA sequence is recognized through Watson-Crick base pairing between the spacer component of the single guide RNA (i.e. its $5^{\prime}$ end) and the complementary strand of the target DNA. Annealing must take place upstream to a PAM (5'-NGG-3'). Double-strand breaks can be repaired by cells either by NHEJ or by HDR. NHEJ is an error-prone process that frequently generates small insertions or deletions. HDR is an alternative pathway that requires the presence of another intact copy of the sequence in the nucleus for repair. If an exogenous DNA template is provided, HDR allows introducing targeted modifications at the double-strand break site.

frameshift mutations in coding sequences, based on NHEJ, to generate null alleles. In ovo NHEJ generates mutations at high rate, often in more than $50 \%$ of the resulting pups. It is in many respects a rapid and efficient alternative to gene knockout. There is however a significant difference between a recessive frameshift mutation and a classical knockout, as the former usually leads to the insertion of selection cassettes.

Table 1 Some major landmarks in CRISPR/Cas9 development.

First description of short repeats located downstream of
the iap gene in $E$. coli
CRISPR, together with associated cas genes, provides
resistance against phages
Cas9 is a RNA-guided endonuclease
CRISPR/Cas9 can be used for genome editing in
mammalian cells, including human stem cells
CRISPR/Cas9 genome editing in mice
CRISPR/Cas9 genome editing in pigs and monkeys
Cloning-free genome editing
RNA-guided nucleases with improved specificity
Controversial use of CRISPR/Cas9 genome editing in
human embryos

\begin{tabular}{c}
\hline Year \\
\hline 1987 \\
2007 \\
2012 \\
2013 \\
2013 \\
2013 \\
2015 \\
2015 \\
2016 \\
\hline
\end{tabular}

$\begin{array}{lr}\text { http://jme.endocrinology-journals.org } & \odot 2016 \text { Society for Endocrinology } \\ \text { DOI: } 10.1530 / \mathrm{JME}-15-0305 & \text { Printed in Great Britain }\end{array}$ 

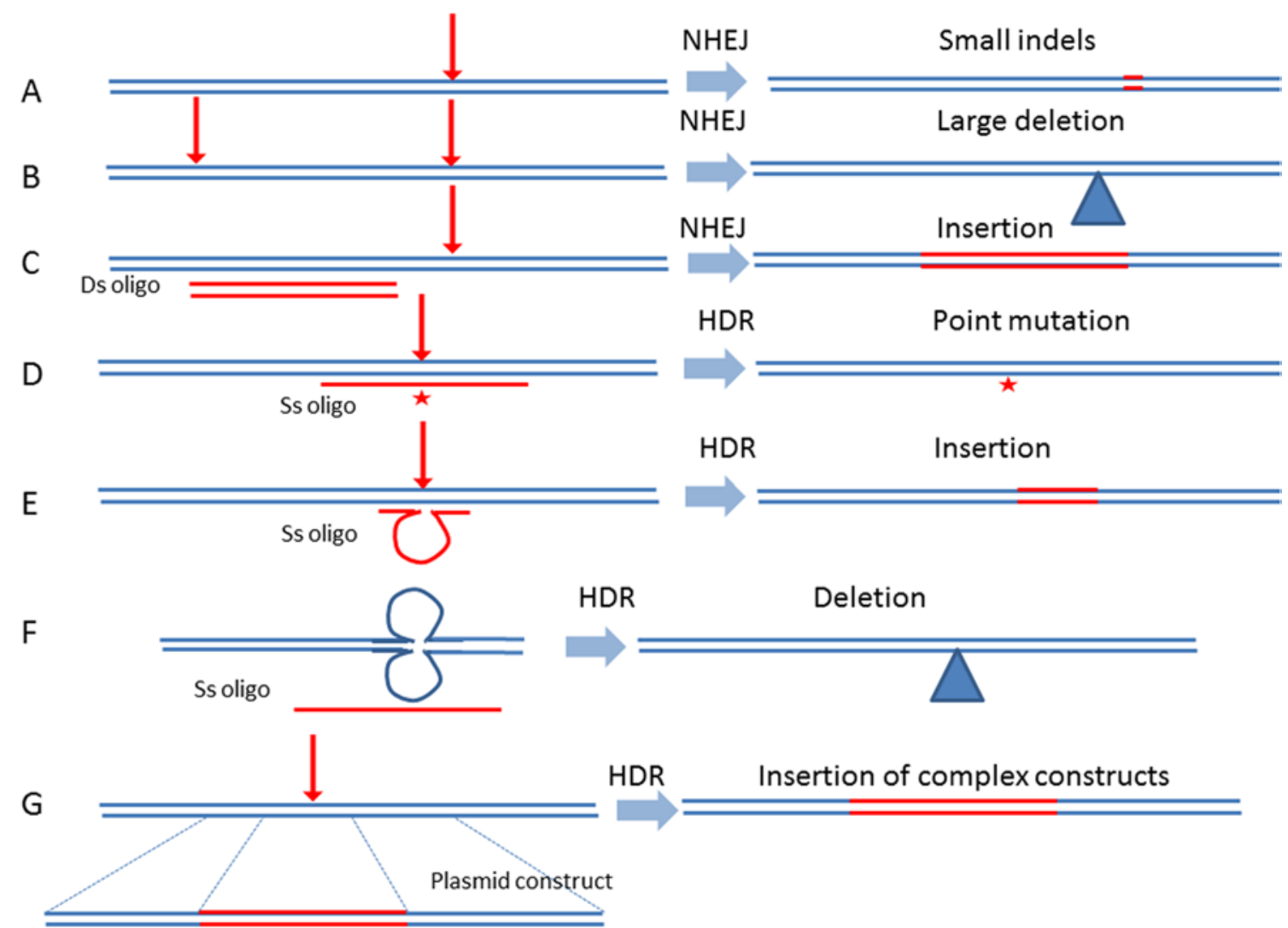

Figure 2

Different uses of CRISPR/Cas9 for genetic manipulation in mice. (A) NHEJ generates small indels. (B) If two different guide RNAs are used to simultaneously cut at two neighboring sites, NHEJ generates large deletions. The size of the deletion can exceed $100 \mathrm{~kb}$. (C) If a double-stranded DNA fragment is introduced in cells together with Cas9/sgRNA, NHEJ sometimes results in the insertion of the exogenous DNA. (D) A single-stranded oligonucleotide, usually a 100-mer, with extensive homology with the target sequence can be used by the cells as a template for HDR. This permits to introduce a point mutation (red star) in the genome. ( $D$ and $E$ ) The same strategy can be used to introduce precisely defined small insertions and deletions. (F) Using plasmids with larger homology arms favors the targeted integration of artificial gene construct in the targeted locus (G).

These superfluous DNA sequences sometimes alter the modified locus in an unexpected manner (Rucker et al. 2000). To inactivate genes by NHEJ, one can also use two sgRNAs simultaneously to generate deletions (Vidigal \& Ventura 2015), whose size can easily exceed $100 \mathrm{~kb}$ (Zhang et al. 2015, Song et al. 2016). Such mutations are easier to detect and provide a better guaranty that gene function is lost. NHEJ can also promote the insertion of exogenous DNA fragments, in a random orientation, if these are provided in large excess (Bachu et al. 2015). Although most experiments are designed to modify single genes, NHEJ has also been used to mutate nine genes simultaneously in fertilized oocytes (Sakurai et al. 2016) or 62 copies of an endogenous viral gene at once in a cell line (Yang et al. 2015). Multiplexing in mouse oocytes seems to be only limited by the necessity to dilute each guide RNA, and the risk of generating unwanted chromosomal rearrangements, if many double-strand breaks are generated simultaneously. In fact, CRISPR/Cas9 can also be applied to generate predefined chromosome rearrangements (Maddalo et al. 2014, Lupianez et al. 2015).

Another important application of CRISPR/Cas9 is to boost the efficiency of homologous recombination, which was previously only achieved in mouse ES cells. When a large DNA construct is introduced in ES cells, containing sequences that are homologous to a genomic locus, it can be spontaneously integrated in the targeted locus. The frequency of targeted integration increases with the size of the homologous sequence but remains usually low. A typical frequency is $1 \%$ of the DNA integration events when the homology spans $10 \mathrm{~kb}$. Generating a doublestrand break in the targeted locus with CRISPR/Cas9 results in an enormous increase in this frequency. The targeted insertion of large plasmid construct therefore becomes possible without using ES cells, by injecting mouse

Published by Bioscientifica Ltd 
oocytes with Cas9 mRNA, sgRNA, and circular plasmid construct (Yang et al. 2013a). Although this remains to be confirmed independently, HDR frequency exceeding 30\% has been reported for constructs with several kilobases of homology (Wang et al. 2015). In ovo, HDR can also be obtained with very short homologies and single-stranded oligonucleotides as templates. For the targeted integration of large constructs, an ingenious protocol suggests to combine several CRISPR-mediated cut and single-stranded oligonucleotides, making dispensable the introduction of any sequence homology between the construct and the targeted genomic locus (Yoshimi et al. 2016).

Currently, the main use of HDR is not to insert exogenous DNA, but to perform in ovo site-directed mutagenesis. A systematic analysis in cultured cells indicates that a 50-mer oligonucleotide with a $2 \mathrm{nt}$ central mismatch already gives an HDR frequency of 1\% (compared with NHEJ) (Yang et al. 2013b), whereas a 100-mer oligonucleotide yields higher efficiencies. The PAM should be absent from the exogenous template, to prevent subsequent DNA cleavage and NHEJ after HDR. In ovo HDR, using synthetic oligonucleotide templates, has been used to introduce single-point mutation (Inui et al. 2014), to insert a $34 \mathrm{bp}$ loxP site, to extend proteincoding sequences to insert small tags, and even to achieve the simultaneous insertion of two loxP sequences at two different sites, in a predefined orientation (Yang et al. 2013a). This single-step generation of 'floxed' alleles represents a spectacular shortcut for an otherwise tedious and time-consuming procedure. However, this astonishing success remains, 3 years after publication, unique in the literature, and it seems unlikely that this direct approach will become a routine.

\section{Delivery of Cas9 and sgRNA to mouse oocytes and the problem of mosaicism}

Different protocols have been used to create targeted germline mutations in mice with CRISPR/Cas9. As the method is relatively novel, a consensus on the best way to operate has not been reached yet. Although we focus here on in ovo protocols, using ES cells still offers some advantages and may not be abandoned: if CRISPR/Cas9 is used to generate complex genetic modifications, occurring at low frequency, it may still be easier to identify the expected genetic events in stem cell clones than directly in newborn mice. In ovo CRISPR/Cas9 remains otherwise a time-saving choice.

The simplest in ovo protocol is to inject a singleplasmid DNA construct, allowing the synthesis of both
Cas9 and sgRNA into mouse fertilized oocytes (Mashiko et al. 2013). In most cases, the microinjected DNA is not integrated in chromosomes and Cas9 expression is only transient. Mutations often appear in the embryo after the first cell divisions, such that most animals are mosaics. This is immediately observable for the tyrosinase gene as homozygous mutations in this gene cause albinism (Mizuno et al. 2014). Mosaicism might result from the time taken for the construct to be transcribed and for Cas9 mRNA to be translated after pronucleus injection in the embryo. However, the first cell division of the mouse embryo takes place within $12-15 \mathrm{~h}$ after pronucleus formation, therefore only few hours after DNA microinjection, whereas the time needed to resolve Cas9 lesions has been estimated to $15 \mathrm{~h}$ (Kim et al. 2014). If applicable to oocytes, this timing is sufficient to explain the late appearance of mutations and the recurrent occurrence of mosaicism. Mosaicism is usually a source of difficulties, but could be sometimes beneficial, when one mosaic founder mouse can give rise to several mutant strains, with different nucleotide sequence changes, generating so-called allelic series. Limiting mosaicism necessitates to accelerate the editing process and to keep it transient. It is thus often preferred to inject premade Cas9 mRNA and sgRNA, both prepared by in vitro transcription with phage polymerases. Although this approach is more efficient than plasmid microinjection (Horii et al. 2014), it does not eliminate mosaicism (Yen et al. 2014). Cas9 protein produced by bacteria can also be purchased from several sources and is efficient in cultured cells (Kim et al. 2014), brain stem cells (Kalebic et al. 2016), and mouse oocytes (Aida et al. 2015). This recombinant protein is mixed with sgRNA in vitro before microinjection. Preparing sgRNAs by direct chemical synthesis (either as sgRNA or as two RNA molecules that will assemble into a guide RNA) goes one step further toward the simplification of the genome editing process, avoiding the need of molecular cloning (Aida et al. 2015, Hendel et al. 2015). Finally, the Cas9 protein can be encoded from a transgene and already present in the fertilized oocytes, in which case a single sgRNA microinjection is sufficient (Sakurai et al. 2016).

\section{The off-target problem}

Like other transgenesis and editing methods, CRISPR/Cas9 is not $100 \%$ specific and can generate 'off-target' mutations. Although off-target mutations are a major issue for any therapeutic applications, they are not as problematic when genome editing is used to generate mutant mouse lines. As long as their occurrence is not

Published by Bioscientifica Ltd 
too high and does not compromise genome integrity and cell viability (Kim et al. 2009), off-target mutations are acceptable, because they will segregate from the intended targeted mutation after germline transmission. The risk of confounding effects is significant only if an off-target mutation is located within $10 \mathrm{Mb}$ of the targeted locus (about $10 \mathrm{cM}$, representing around $1 \%$ of the genome) or if the phenotype of 'F0' mice has to be analyzed.

The extent to which off-target mutations occur has been quite controversial ( $\mathrm{O}^{\prime} \mathrm{Geen}$ et al. 2015b). It is apparently less common in mouse zygotes than in cell lines (Iyer et al. 2015). Cas9 tolerates mismatches throughout the guide sequence in a manner that is sensitive to the number, position, and distribution of the mismatches (Hsu et al. 2013). Although computational prediction reliability remains limited, it is advisable to carefully search the genome sequence with appropriate software solutions (see below) and to ascertain that the predicted off-target mutations are not located in exonic fraction of the genome. Several methods based on deep sequencing, including GUIDE-Seq (Tsai et al. 2015), digenome-seq (Kim et al. 2015, 2016), BLESS (Crosetto et al. 2013), and HTGTS (Frock et al. 2015), have been developed to detect de novo mutations on a genome-wide scale. When CRISPR/Cas9 is used to integrate exogenous DNA constructs, fluorescent in situ hybridization on metaphase chromosomes can also be performed (Paulis et al. 2015). They all confirm the existence of off-target mutations, whose locations were not always predicted, but also indicate that the frequency of these events is low in most experimental applications.

It is important to stress that CRISPR/Cas9 is a twostep process (Sternberg et al. 2014, Jiang et al. 2015): Cas9 only needs the annealing of $10 \mathrm{nt}$ of the guide RNA to bind DNA, whereas its endonuclease activity requires the annealing of more than $16 \mathrm{nt}$ to the genomic target (Kiani et al. 2015). Direct microscopy study indicates that offtarget binding events are, on average, short-lived (Knight et al. 2015). ChipSeq analysis confirms that, although sgRNA allows Cas9 to bind to thousands of genomic sites, mutations are detected almost exclusively at the targeted locus (Kuscu et al. 2014, Wu et al. 2014, O'Geen et al. 2015a). Although there is little correlation between the chromatin occupancy by Cas 9 and the occurrence of double-strand breaks leading to mutations (Tsai et al. 2015), chromatin accessibility has a significant influence on editing efficiency (Chari et al. 2015).

A number of possibilities have been explored to reduce the frequency of off-target mutation. Shorter sgRNAs tend to have fewer off-target sites, and an homology stretch of $17 \mathrm{nt}$ was proposed to be a better option than the most common $20 \mathrm{nt}$ choice (Fu et al. 2014). Adding two extra $\mathrm{G}$ at the $5^{\prime}$ end of the sgRNA, which do not match the genomic sequence, can also increase cleavage specificity, but sometimes reduces cleavage efficiency (Cho et al. 2014). A way to drastically reduce the frequency of off-target effects is by using Cas9D10A, a Cas9 with an amino acid change that alters one of the two active sites of the nuclease. This turns Cas9D10A into a 'nickase', which only cuts one DNA strand (Mali et al. 2013a, Ran et al. 2013a, Shen et al. 2014a). Cas9D10A nickase is not mutagenic, unless two sgRNAs are combined to target two opposite strands simultaneously, introducing two independent single-strand breaks at nearby sites (Shen et al. 2014a). In that case, the specificity of doublestranded DNA cleavage relies on the formation of two neighboring 17-20nt RNA:DNA heteroduplexes instead of one. Another interesting attempt to limit off-target cleavages is the use of the Cas9-Fok1 fusion protein, in which the nuclease activity of Cas9 is eliminated and replaced by the nuclease activity of Fok1, which can only cleave DNA as a homodimer. Therefore, Cas9-Fok1 cuts only if two sgRNAs target neighboring genomic sequences (Hara et al. 2015). Both strategies require that two PAM sequences are found at the appropriate distance on opposite strands in the targeted locus. A similar approach is to combine CRISPR and zinc finger proteins (Bolukbasi et al. 2015). Although the reduction in the rate of off-target mutations was experimentally demonstrated (Cho et al. 2014), the available data do not permit to fully evaluate whether these alternate strategies maintain the efficacy of on-target genome editing. The most promising developments have come very recently (Kleinstiver et al. 2015, Slaymaker et al. 2015). It consists in a rational engineering of modified Cas9, with amino acid substitutions introduced to increase the sensitivity to single- and double-base mismatches between the guide RNA and the target DNA. The enhanced nucleases, called eSpCas9 and SpCas9-HF1, display a significant decrease in their capacity to generate off-target mutations, without loss of on-target efficiency. If these enhanced nucleases fulfill the expectations, they should rapidly replace the original version of the nuclease.

\section{Guide RNA design}

Genome editing by CRISPR/Cas9 can be performed at virtually any genomic site with a PAM: 5'-NGG-3'. When such a PAM cannot be used, alternatives can be used. First, Cas9 can cleave sites with $5^{\prime}-\mathrm{NAG}-3^{\prime}$ or 5'-NGA-3' PAM albeit less efficiently (Hsu et al. 2013).

Published by Bioscientifica Ltd. 
Cas9 has also been engineered to alter PAM specificity (Kleinstiver et al. 2015). Furthermore, microorganisms host a variety of other RNA-guided nucleases, the use of which as genome editing tools is just starting to be explored (Shmakov et al. 2015). Streptococcus thermophilus Cas9 uses the 5'-NNAGAAW-3' sequence as PAM, but has lower cleavage efficiencies than $S$. pyogenes Cas9. Structure-guided engineering of Francisella novicida Cas9 produced a variant specific for the relaxed 5'-YG-3' PAM (Hirano et al. 2016). The recently studied Cpf1 nuclease, which belongs to a different class of CRISPR-Cas system (Zetsche et al. 2015a), has distinct properties that make it promising for future development: it uses a T-rich PAM, a shorter sgRNA (42nt), and cuts the two DNA strands at different positions, leaving $5^{\prime}$ overhangs that should facilitate foreign DNA insertion.

A growing number of free bioinformatics tools have been developed to help in sgRNA design. The aim is to maximize the cutting efficiency while minimizing off-target cleavages (Ren et al. 2014, Koo et al. 2015, MacPherson \& Scherf 2015, Park et al. 2015, Oliveros et al. 2016). The sequence of predesigned sgRNA is also available for the whole mouse exome (http://www. sanger.ac.uk/htgt/wge/) (Hodgkins et al. 2015). Most software tools evaluate the probability of off-target mutations, based on sequence similarities. However, experimental data indicate a poor predictive capacity of these algorithms (Tsai et al. 2015). Some programs also try to predict the on-target cutting efficiency, based on large experimental datasets (Doench et al. 2014, Liu et al. 2016). The most recent one, sgRNA Scorer, takes into account the observation that a $G$ located immediately upstream to the PAM greatly increases genome editing efficiency (Chari et al. 2015). The size of the sgRNA 5' end that is complementary to the genomic sequence is between 17 and $20 \mathrm{nt}$. The most common choice is $20 \mathrm{nt}$ as most investigators assume that a longer sequence will stabilize RNA:DNA hybrids and increase Cas9 cutting efficiency. However, $17 \mathrm{nt}$ has been claimed to be an optimal compromise between efficiency and specificity (Fu et al. 2014). In any case, it is usual to test at least two sgRNAs for a given targeted genomic site, as cleavage efficiency remains difficult to predict and to avoid superfluous nucleotides in sgRNA. However, in vitro transcription by phage polymerases imposes a 5' GG dinucleotide (Stump \& Hall 1993), whereas in vivo transcription initiation from the U6 promoter by RNA polymerase III starts with a G. It is thus necessary to append at least one extra $G$ at the $5^{\prime}$ of the sgRNA if the 17-20 nt guide sequence does not begin with $\mathrm{G}$.

\section{Favoring HDR vs NHEJ}

When short DNA templates are used, NHEJ is largely predominant over HDR after double-strand break in fertilized mouse embryos. It is thus easier to generate random indels in the targeted locus than to perform a predefined modification of the sequence. Having full control over the genetic modification is however much more desirable and requires favoring HDR over NHEJ. Impressive HDR rates have been obtained with longsynthetic single-stranded oligonucleotide templates in a cell line, by following two simple rules (Richardson et al. 2016): (1) the sequence of the oligonucleotide should be identical to that of the 'target strand' (i.e., complementary to the sgRNA), and (2) the position of the sequence should be asymmetrical, being longer on the PAM-proximal side of the double-stranded DNA break. A chemical modification of the single-stranded template oligonucleotide, introduced to increase its stability, also favors in ovo HDR (Renaud et al. 2016). In addition, a recent study showed that HDR accuracy can be dramatically increased by incorporating silent mutations, along with the desired mutation, to prevent subsequent NHEJ events (Paquet et al. 2016). The knowledge of the molecular mechanisms that underlie each DNA repair pathway offers some other interesting possibilities for manipulating the outcome of the repair. Scr7 is an anticancer agent that inhibits DNA ligase IV, and thus hampers NHEJ, favoring the occurrence of HDR in both cultured cells and mouse embryos without apparent toxicity (Maruyama et al. 2015). However, Scr7 did not significantly increase the frequency of in ovo HDR for large DNA templates (Wang et al. 2015). The same inhibition of NHEJ can be obtained by knocking down the mRNA of ligase IV or KU70 with shRNA. Adenovirus 4 (Ad4) E1B55K and E4orf6 proteins, which mediate the ubiquitination and proteasomal degradation of DNA ligase IV, also inhibit NHEJ and increase HDR/NHEJ ratio (Chu et al. 2015). An ingenious alternative strategy is to destabilize Cas9 during the G1 and S phases of the cell cycle, by fusing it to a domain of Geminin, as HDR mainly takes place during the G2 phase (Gutschner et al. 2016). Finally, pharmacological screening identified several small molecules that also favor HDR compared with NHEJ (Yu et al. 2015). It is currently too early to clearly evaluate the benefit of all these approaches.

\section{Using nuclease-defective Cas9 to engineer new RNA-guided proteins}

The general concept that a protein can be targeted to a specific genomic locus by a guide RNA has far-reaching

Published by Bioscientifica Ltd 
consequences. Nuclease-deficient versions of Cas9 have already been engineered to direct a variety of effectors to target loci. This strategy has been used to activate (Maeder et al. 2013, Tanenbaum et al. 2014, Zetsche et al. 2015b) and repress transcription either by tethering a transcriptional repressor (Gilbert et al. 2013, Qi et al. 2013) or by inducing DNA methylation in regulatory sequences (McDonald et al. 2016). Inhibition and activation of different genes can even be achieved within the same cell (Zalatan et al. 2015). This is a field of very active investigation, as genome editing could perhaps advantageously be replaced by targeted deregulation of gene expression. However, the fact that the native form of Cas9 binds DNA at many genomic sites, but introduces double-strand breaks in only few of them, where sequence homology is maximal (Wu et al. 2014), raises a major concern about the possible specificity of these approaches. A clever recent novelty was the fusion of nuclease-defective Cas9 and a cytidine deaminase enzyme (Komor et al. 2016). This hybrid RNA-guided enzyme mediates the direct conversion of cytidine to uridine, thereby effecting a $\mathrm{C} \rightarrow \mathrm{T}$ (or $\mathrm{G} \rightarrow \mathrm{A}$ ) substitution. This makes the outcome of genome editing more predictable than the one mediated by NHEJ. More work is required to fully evaluate all these strategies, as most of the new developments are very recent, and often still preliminary.

\section{CRISPR/Cas9 and the future of endocrinology}

Only the novelty of the CRISPR/Cas9 genome editing technology explains why only few publications already used it for endocrine research. One can however foresee deep changes in the way genetic investigations will be performed. One immediate advantage is that it will renew interest for cellular models, primary cultures, or cell lines, in which the capacity to perform genome editing will bring a lot of interesting possibilities. Genomewide genetic screen will permit to bring system biology, currently limited to few model cell lines, to more relevant cellular models. For example, it may help to define the functions of the thousands of binding sites that have been identified for several nuclear hormone receptors by ChipSeq analysis.

Most of all, CRISPR/Cas9 makes genetic engineering in mice easier, faster, and cheaper. Considering that synthetic guide RNA can be synthetized quickly, transgenic pups homozygous for knockout mutation can be produced using the cloning-free procedure within 1 month. If the phenotype manifests at birth, the entire process could take not more than 1 month. Considering the problems of mosaicism and offtarget mutations, immediate phenotyping of these F0 animals remains risky, but already provides important indications. By contrast, the equivalent experiment performed with the traditional ES-based protocol would take on average more than 1 year. It is even possible to target several genes simultaneously, as up to nine different sgRNAs can be microinjected in oocytes at the same time (Sakurai et al. 2016). One main outcome should be that genetic investigations of a gene function in mice will not be limited to the analysis of a single-mutated allele anymore, but will be expanded to allelic series, as this is common practice in D. melanogaster. This will produce a range of phenotypic severity and identify the respective functions of the different proteins that a single gene often produces. Introducing single amino acid substitutions to alter different protein-protein interactions separately will uncouple the different functions of a protein. Another possibility will be to produce 'custom-made' models for human genetic diseases in which mice will carry a point mutation equivalent to that found in a given patient. Finally, tackling the poorly explored noncoding part of the genome, that is, the noncoding RNAs and regulatory sequences, becomes feasible (Korkmaz et al. 2016). The production of new transgenic lines is not a rate-limiting step anymore. Only the difficulty of maintaining and phenotyping many mouse strains will constrain research projects.

The other expected change is that genome editing should become feasible for any laboratory animal from which fertilized oocytes can be explanted and reimplanted. CRISPR/Cas9 has already been used in rats (Menoret et al. 2014), hamster (Fan et al. 2014), and rabbit (Yuan et al. 2016), which all bring some specific benefit in endocrinology (Duranthon et al. 2012, Boucsein et al. 2016). These alternative models will certainly provide a useful complement and might eventually challenge the predominance of mice as model species to study mammalian physiology.

Finally, the advent of CRISPR/Cas9 may rejuvenate the traditional genetic approach of biological questions. We considered here only the reverse genetic approach, in which the relation between genes and characters is studied from bottom to top: mutations are first produced for a known gene, and then the unknown phenotypic consequences of the gene mutation are analyzed.

Published by Bioscientifica Ltd 
Classical genetics goes in the opposite direction, and first chooses a character before searching for the genes that determine it. Chemical (ENU) mutagenesis has sometimes been used for this purpose in mice, but experience proves that identifying the causative mutations of a phenotypic trait remains in this case a daunting challenge (Weiss et al. 2012). Several CRISPR libraries are already available, offering the possibility to set phenotype-based screening strategies, by introducing NHEJ-based frameshift mutations in virtually all the genes. This approach has already been implemented in cell lines (Wang et al. 2014), zebrafish (Varshney et al. 2015), and Drosophila (Bassett et al. 2015). It is in essence similar to ENU mutagenesis but has a key advantage: here the DNA corresponding to sgRNA persists in a variant individual and can easily be sequenced a posteriori. Therefore, the gene that has been mutated can be easily inferred from the sgRNA sequence. A second round of confirmatory experiments, performed on a gene-by-gene approach, could confirm the gene identification process. The rate-limiting step for such a CRISPR-based genetic screening in mice is oocyte microinjection, which could be replaced by oocyte electroporation (Hashimoto \& Takemoto 2015, Qin et al. 2015, Takahashi et al. 2015). In that respect, somatic gene transfer is certainly an alternative to consider (Mikuni et al. 2016, Williams et al. 2016, Yang et al. 2016). If in vivo screening has to be done by oocyte microinjection, it would be facilitated if germline transmission of mutations was not required. This would imply that a large fraction of F0 animals are homozygous, as many of the mutations are recessive. A way to increase the rate of homozygosity is a genetic trick, called mutagenic chain reaction, which consists in integrating the Cas9 reading frame itself within the mutated locus (Gantz \& Bier 2015).

The gold rush that follows a major technical innovation is usually followed by a phase of soberness, where the limitations of the new technology become visible. We are not at this point yet for genome editing and important progresses are still expected.

\section{Declaration of interest}

The authors declare that there is no conflict of interest that could be perceived as prejudicing the impartiality of this review.

\section{Funding}

This work did not receive any specific grant from any funding agency in the public, commercial, or not-for-profit sector.

\section{Acknowledgments}

We thank M Averof and K Gauthier for critical reading of the manuscript. The work in our laboratory was supported by Agence National pour la Recherche (Thyromut2 ANR15-CE14-0011-01).

\section{References}

Aida T, Chiyo K, Usami T, Ishikubo H, Imahashi R, Wada Y, Tanaka KF, Sakuma T, Yamamoto T \& Tanaka K 2015 Cloning-free CRISPR/Cas system facilitates functional cassette knock-in in mice. Genome Biology 16 87. (doi:10.1186/s13059-015-0653-x)

Bachu R, Bergareche I \& Chasin LA 2015 CRISPR-Cas targeted plasmid integration into mammalian cells via non-homologous end joining. Biotechnology and Bioengineering 112 2154-2162. (doi:10.1002/ bit.25629)

Barrangou R, Fremaux C, Deveau H, Richards M, Boyaval P, Moineau S, Romero DA \& Horvath P 2007 CRISPR provides acquired resistance against viruses in prokaryotes. Science 315 1709-1712. (doi:10.1126/ science.1138140)

Bassett AR, Kong L \& Liu JL 2015 A genome-wide CRISPR library for high-throughput genetic screening in Drosophila cells. Journal of Genetics and Genomics 42 301-309. (doi:10.1016/j.jgg.2015.03.011)

Bolukbasi MF, Gupta A, Oikemus S, Derr AG, Garber M, Brodsky MH, Zhu LJ \& Wolfe SA 2015 DNA-binding-domain fusions enhance the targeting range and precision of Cas9. Nature Methods 12 1150-1156. (doi:10.1038/nmeth.3624)

Boucsein A, Benzler J, Hempp C, Stohr S, Helfer G \& Tups A 2016 Photoperiodic and diurnal regulation of WNT signaling in the arcuate nucleus of the female Djungarian hamster, Phodopus sungorus. Endocrinology 157 799-809. (doi:10.1210/en.2015-1708)

Capecchi MR 2005 Gene targeting in mice: functional analysis of the mammalian genome for the twenty-first century. Nature Reviews Genetics 6 507-512. (doi:10.1038/nrg1619)

Chari R, Mali P, Moosburner M \& Church GM 2015 Unraveling CRISPRCas9 genome engineering parameters via a library-on-library approach. Nature Methods 12 823-826. (doi:10.1038/nmeth.3473)

Cho SW, Kim S, Kim Y, Kweon J, Kim HS, Bae S \& Kim JS 2014 Analysis of off-target effects of CRISPR/Cas-derived RNA-guided endonucleases and nickases. Genome Research 24 132-141. (doi:10.1101/ gr.162339.113)

Chu VT, Weber T, Wefers B, Wurst W, Sander S, Rajewsky K \& Kuhn R 2015 Increasing the efficiency of homology-directed repair for CRISPR-Cas9-induced precise gene editing in mammalian cells. Nature Biotechnology 33 543-548. (doi:10.1038/nbt.3198)

Cong L, Ran FA, Cox D, Lin S, Barretto R, Habib N, Hsu PD, Wu X, Jiang W, Marraffini LA, et al. 2013 Multiplex genome engineering using CRISPR/Cas systems. Science 339 819-823. (doi:10.1126/ science.1231143)

Crosetto N, Mitra A, Silva MJ, Bienko M, Dojer N, Wang Q, Karaca E, Chiarle R, Skrzypczak M, Ginalski K, et al. 2013 Nucleotideresolution DNA double-strand break mapping by next-generation sequencing. Nature Methods 10 361-365. (doi:10.1038/nmeth.2408)

Davey RA \& MacLean HE 2006 Current and future approaches using genetically modified mice in endocrine research. American Journal of Physiology: Endocrinology and Metabolism 291 E429-E438.

Doench JG, Hartenian E, Graham DB, Tothova Z, Hegde M, Smith I, Sullender M, Ebert BL, Xavier RJ \& Root DE 2014 Rational design of highly active sgRNAs for CRISPR-Cas9-mediated gene inactivation. Nature Biotechnology 32 1262-1267. (doi:10.1038/nbt.3026)

Duranthon V, Beaujean N, Brunner M, Odening KE, Santos AN, Kacskovics I, Hiripi L, Weinstein EJ \& Bosze Z 2012 On the emerging role of rabbit as human disease model and the instrumental role of novel transgenic tools. Transgenic Research 21 699-713. (doi:10.1007/ s11248-012-9599-x) 
Fan Z, Li W, Lee SR, Meng Q, Shi B, Bunch TD, White KL, Kong IK \& Wang Z 2014 Efficient gene targeting in golden Syrian hamsters by the CRISPR/Cas9 system. PLOS ONE 9 e109755.

Frock RL, Hu J, Meyers RM, Ho YJ, Kii E \& Alt FW 2015 Genome-wide detection of DNA double-stranded breaks induced by engineered nucleases. Nature Biotechnology 33 179-186. (doi:10.1038/nbt.3101)

Fu Y, Sander JD, Reyon D, Cascio VM \& Joung JK 2014 Improving CRISPR-Cas nuclease specificity using truncated guide RNAs. Nature Biotechnology 32 279-284. (doi:10.1038/nbt.2808)

Gantz VM \& Bier E 2015 Genome editing. The mutagenic chain reaction: a method for converting heterozygous to homozygous mutations. Science 348 442-444. (doi:10.1126/science.aaa5945)

Garneau JE, Dupuis ME, Villion M, Romero DA, Barrangou R, Boyaval P, Fremaux C, Horvath P, Magadan AH \& Moineau S 2010 The CRISPR/ Cas bacterial immune system cleaves bacteriophage and plasmid DNA. Nature 468 67-71. (doi:10.1038/nature09523)

Gilbert LA, Larson MH, Morsut L, Liu Z, Brar GA, Torres SE, SternGinossar N, Brandman O, Whitehead EH, Doudna JA, et al. 2013 CRISPR-mediated modular RNA-guided regulation of transcription in eukaryotes. Cell 154 442-451. (doi:10.1016/j.cell.2013.06.044)

Gu H, Marth JD, Orban PC, Mossmann H \& Rajewsky K 1994 Deletion of a DNA polymerase beta gene segment in T cells using cell typespecific gene targeting. Science 265 103-106. (doi:10.1126/ science.8016642)

Gutschner T, Haemmerle M, Genovese G, Draetta GF \& Chin L 2016 Post-translational regulation of Cas9 during G1 enhances homologydirected repair. Cell Reports 14 1555-1566. (doi:10.1016/j. celrep.2016.01.019)

Hara S, Tamano M, Yamashita S, Kato T, Saito T, Sakuma T, Yamamoto T, Inui M \& Takada S 2015 Generation of mutant mice via the CRISPR/ Cas9 system using FokI-dCas9. Scientific Reports 511221. (doi:10.1038/srep11221)

Hashimoto M \& Takemoto T 2015 Electroporation enables the efficient mRNA delivery into the mouse zygotes and facilitates CRISPR/Cas9based genome editing. Scientific Reports 5 11315. (doi:10.1038/ srep11315)

Hendel A, Bak RO, Clark JT, Kennedy AB, Ryan DE, Roy S, Steinfeld I, Lunstad BD, Kaiser RJ, Wilkens AB, et al. 2015 Chemically modified guide RNAs enhance CRISPR-Cas genome editing in human primary cells. Nature Biotechnology 33 985-989. (doi:10.1038/nbt.3290)

Hirano H, Gootenberg JS, Horii T, Abudayyeh OO, Kimura M, Hsu PD, Nakane T, Ishitani R, Hatada I, Zhang F, et al. 2016 Structure and Engineering of Francisella novicida Cas9. Cell 164 950-961. (doi:10.1016/j.cell.2016.01.039)

Hodgkins A, Farne A, Perera S, Grego T, Parry-Smith DJ, Skarnes WC \& Iyer V 2015 WGE: a CRISPR database for genome engineering. Bioinformatics 31 3078-3080. (doi:10.1093/bioinformatics/btv308)

Horii T, Arai Y, Yamazaki M, Morita S, Kimura M, Itoh M, Abe Y \& Hatada I 2014 Validation of microinjection methods for generating knockout mice by CRISPR/Cas-mediated genome engineering. Scientific Reports 44513.

Hsu PD, Scott DA, Weinstein JA, Ran FA, Konermann S, Agarwala V, Li Y, Fine EJ, Wu X, Shalem O, et al. 2013 DNA targeting specificity of RNA-guided Cas9 nucleases. Nature Biotechnology 31 827-832. (doi:10.1038/nbt.2647)

Inui M, Miyado M, Igarashi M, Tamano M, Kubo A, Yamashita S, Asahara H, Fukami M \& Takada S 2014 Rapid generation of mouse models with defined point mutations by the CRISPR/Cas9 system. Scientific Reports 45396.

Ishino Y, Shinagawa H, Makino K, Amemura M \& Nakata A 1987 Nucleotide sequence of the iap gene, responsible for alkaline phosphatase isozyme conversion in Escherichia coli, and identification of the gene product. Journal of Bacteriology 169 5429-5433.

Iyer V, Shen B, Zhang W, Hodgkins A, Keane T, Huang X \& Skarnes WC 2015 Off-target mutations are rare in Cas9-modified mice. Nature Methods 12 479. (doi:10.1038/nmeth.3408)
Jiang F, Zhou K, Ma L, Gressel S \& Doudna JA 2015 STRUCTURAL BIOLOGY. A Cas9-guide RNA complex preorganized for target DNA recognition. Science 348 1477-1481. (doi:10.1126/science.aab1452)

Kalebic N, Taverna E, Tavano S, Wong FK, Suchold D, Winkler S, Huttner WB \& Sarov M 2016 CRISPR/Cas9-induced disruption of gene expression in mouse embryonic brain and single neural stem cells in vivo. EMBO Reports 17 338-348. (doi:10.15252/ embr.201541715)

Kang X, He W, Huang Y, Yu Q, Chen Y, Gao X, Sun X \& Fan Y 2016 Introducing precise genetic modifications into human 3PN embryos by CRISPR/Cas-mediated genome editing. Journal of Assisted Reproduction and Genetics 33 581-588. (doi:10.1007/s10815-016-0710-8)

Kiani S, Chavez A, Tuttle M, Hall RN, Chari R, Ter-Ovanesyan D, Qian J, Pruitt BW, Beal J, Vora S, et al. 2015 Cas9 gRNA engineering for genome editing, activation and repression. Nature Methods 12 10511054. (doi:10.1038/nmeth.3580)

Kim HJ, Lee HJ, Kim H, Cho SW \& Kim JS 2009 Targeted genome editing in human cells with zinc finger nucleases constructed via modular assembly. Genome Research 19 1279-1288. (doi:10.1101/ gr.089417.108)

Kim S, Kim D, Cho SW, Kim J \& Kim JS 2014 Highly efficient RNAguided genome editing in human cells via delivery of purified Cas9 ribonucleoproteins. Genome Research 24 1012-1019.

Kim D, Bae S, Park J, Kim E, Kim S, Yu HR, Hwang J, Kim JI \& Kim JS 2015 Digenome-seq: genome-wide profiling of CRISPR-Cas9 offtarget effects in human cells. Nature Methods 12 237-243. (doi:10.1038/nmeth.3284)

Kim D, Kim S, Kim S, Park J \& Kim JS 2016 Genome-wide target specificities of CRISPR-Cas9 nucleases revealed by multiplex Digenome-seq. Genome Research 26 406-415. (doi:10.1101/ gr.199588.115)

Kleinstiver BP, Prew MS, Tsai SQ, Topkar VV, Nguyen NT, Zheng Z, Gonzales AP, Li Z, Peterson RT, Yeh JR, et al. 2015 Engineered CRISPR-Cas9 nucleases with altered PAM specificities. Nature $\mathbf{5 2 3}$ 481-485. (doi:10.1038/nature14592)

Kleinstiver BP, Pattanayak V, Prew MS, Tsai SQ, Nguyen NT, Zheng Z \& Joung JK 2016 High-fidelity CRISPR-Cas9 nucleases with no detectable genome-wide off-target effects. Nature 529 490-495. (doi:10.1038/nature16526)

Knight SC, Xie L, Deng W, Guglielmi B, Witkowsky LB, Bosanac L, Zhang ET, El Beheiry M, Masson JB, Dahan M, et al. 2015 Dynamics of CRISPR-Cas9 genome interrogation in living cells. Science $\mathbf{3 5 0}$ 823-826. (doi:10.1126/science.aac6572)

Komor AC, Kim YB, Packer MS, Zuris JA \& Liu DR 2016 Programmable editing of a target base in genomic DNA without double-stranded DNA cleavage. Nature 533 420-424. (doi:10.1038/nature17946)

Koo T, Lee J \& Kim JS 2015 Measuring and reducing off-target activities of programmable nucleases including CRISPR-Cas9. Molecules and Cells 38 475-481. (doi:10.14348/molcells.2015.0103)

Korkmaz G, Lopes R, Ugalde AP, Nevedomskaya E, Han R, Myacheva K, Zwart W, Elkon R \& Agami R 2016 Functional genetic screens for enhancer elements in the human genome using CRISPR-Cas9. Nature Biotechnology 34 192-198. (doi:10.1038/nbt.3450)

Kuhn R, Schwenk F, Aguet M \& Rajewsky K 1995 Inducible gene targeting in mice. Science 269 1427-1429. (doi:10.1126/ science.7660125)

Kuscu C, Arslan S, Singh R, Thorpe J \& Adli M 2014 Genome-wide analysis reveals characteristics of off-target sites bound by the Cas9 endonuclease. Nature Biotechnology 32 677-683. (doi:10.1038/ nbt.2916)

Liu X, Homma A, Sayadi J, Yang S, Ohashi J \& Takumi T 2016 Sequence features associated with the cleavage efficiency of CRISPR/Cas9 system. Scientific Reports 6 19675. (doi:10.1038/srep19675)

Lupianez DG, Kraft K, Heinrich V, Krawitz P, Brancati F, Klopocki E, Horn D, Kayserili H, Opitz JM, Laxova R, et al. 2015 Disruptions of topological chromatin domains cause pathogenic rewiring of 
gene-enhancer interactions. Cell 161 1012-1025. (doi:10.1016/ j.cell.2015.04.004)

MacPherson CR \& Scherf A 2015 Flexible guide-RNA design for CRISPR applications using Protospacer Workbench. Nature Biotechnology 33 805-806.

Maddalo D, Manchado E, Concepcion CP, Bonetti C, Vidigal JA, Han YC, Ogrodowski P, Crippa A, Rekhtman N, de Stanchina E, et al. 2014 In vivo engineering of oncogenic chromosomal rearrangements with the CRISPR/Cas9 system. Nature 516 423-427. (doi:10.1038/ nature13902)

Maeder ML, Linder SJ, Cascio VM, Fu Y, Ho QH \& Joung JK 2013 CRISPR RNA-guided activation of endogenous human genes. Nature Methods 10 977-979. (doi:10.1038/nmeth.2598)

Mali P, Aach J, Stranges PB, Esvelt KM, Moosburner M, Kosuri S, Yang L \& Church GM 2013a CAS9 transcriptional activators for target specificity screening and paired nickases for cooperative genome engineering. Nature Biotechnology 31 833-838.

Mali P, Yang L, Esvelt KM, Aach J, Guell M, DiCarlo JE, Norville JE \& Church GM 2013b RNA-guided human genome engineering via Cas9. Science 339 823-826.

Maruyama T, Dougan SK, Truttmann MC, Bilate AM, Ingram JR \& Ploegh HL 2015 Increasing the efficiency of precise genome editing with CRISPR-Cas9 by inhibition of nonhomologous end joining. Nature Biotechnology 33 538-542. (doi:10.1038/nbt.3190)

Mashiko D, Fujihara Y, Satouh Y, Miyata H, Isotani A \& Ikawa M 2013 Generation of mutant mice by pronuclear injection of circular plasmid expressing Cas9 and single guided RNA. Scientific Reports 3 3355.

McDonald JI, Celik H, Rois LE, Fishberger G, Fowler T, Rees R, Kramer A, Martens A, Edwards JR \& Challen GA 2016 Reprogrammable CRISPR/ Cas9-based system for inducing site-specific DNA methylation. Biology Open 5 866-874. (doi:10.1242/bio.019067)

Menoret S, de Cian A, Tesson L, Remy S, Fontaniere S, Thinard R, Usal C, Savignard C, Fraichard A, Nguyen TH, et al. 2014 Knockin (KI) in rat zygotes with TALENs and CRISPR/Cas9 systems as protein forms. Transgenic Research 23 883-883.

Mikuni T, Nishiyama J, Sun Y, Kamasawa N \& Yasuda R 2016 Highthroughput, high-resolution mapping of protein localization in mammalian brain by in vivo genome editing. Cell 165 1803-1817. (doi:10.1016/j.cell.2016.04.044)

Mizuno S, Dinh TT, Kato K, Mizuno-Iijima S, Tanimoto Y, Daitoku Y, Hoshino Y, Ikawa M, Takahashi S, Sugiyama F, et al. 2014 Simple generation of albino C57BL/6J mice with G291T mutation in the tyrosinase gene by the CRISPR/Cas9 system. Mammalian Genome 25 327-334. (doi:10.1007/s00335-014-9524-0)

Niu Y, Shen B, Cui Y, Chen Y, Wang J, Wang L, Kang Y, Zhao X, Si W, Li W, et al. 2014 Generation of gene-modified cynomolgus monkey via Cas9/RNA-mediated gene targeting in one-cell embryos. Cell $\mathbf{1 5 6}$ 836-843. (doi:10.1016/j.cell.2014.01.027)

O'Geen H, Henry IM, Bhakta MS, Meckler JF \& Segal DJ 2015a A genome-wide analysis of Cas9 binding specificity using ChIP-seq and targeted sequence capture. Nucleic Acids Research 43 3389-3404.

O'Geen H, Yu AS \& Segal DJ 2015b How specific is CRISPR/Cas9 really? Current Opinion in Chemical Biology 29 72-78.

Oliveros JC, Franch M, Tabas-Madrid D, San-Leon D, Montoliu L, Cubas P \& Pazos F 2016 Breaking-Cas-interactive design of guide RNAs for CRISPR-Cas experiments for ENSEMBL genomes. Nucleic Acids Research gkw407. (doi:10.1093/nar/gkw407)

Pabo CO, Peisach E \& Grant RA 2001 Design and selection of novel Cys2His2 zinc finger proteins. Annual Review of Biochemistry 70 313-340. (doi:10.1146/annurev.biochem.70.1.313)

Palmiter RD \& Brinster RL 1985 Transgenic mice. Cell 41 343-345. (doi:10.1016/S0092-8674(85)80004-0)

Paquet D, Kwart D, Chen A, Sproul A, Jacob S, Teo S, Olsen KM, Gregg A, Noggle S \& Tessier-Lavigne M 2016 Efficient introduction of specific homozygous and heterozygous mutations using CRISPR/ Cas9. Nature 533 125-129. (doi:10.1038/nature17664)

Park J, Bae S \& Kim JS 2015 Cas-Designer: a web-based tool for choice of CRISPR-Cas9 target sites. Bioinformatics 31 4014-4016.

Paulis M, Castelli A, Lizier M, Susani L, Lucchini F, Villa A \& Vezzoni P 2015 A pre-screening FISH-based method to detect CRISPR/Cas9 offtargets in mouse embryonic stem cells. Scientific Reports 512327. (doi:10.1038/srep12327)

Qi LS, Larson MH, Gilbert LA, Doudna JA, Weissman JS, Arkin AP \& Lim WA 2013 Repurposing CRISPR as an RNA-guided platform for sequence-specific control of gene expression. Cell 152 1173-1183. (doi:10.1016/j.cell.2013.02.022)

Qin W, Dion SL, Kutny PM, Zhang Y, Cheng AW, Jillette NL, Malhotra A, Geurts AM, Chen YG \& Wang H 2015 Efficient CRISPR/Cas9-mediated genome editing in mice by zygote electroporation of nuclease. Genetics 200 423-430. (doi:10.1534/ genetics.115.176594)

Ran FA, Hsu PD, Lin CY, Gootenberg JS, Konermann S, Trevino AE, Scott DA, Inoue A, Matoba S, Zhang Y, et al. 2013a Double nicking by RNA-guided CRISPR Cas9 for enhanced genome editing specificity. Cell 154 1380-1389.

Ran FA, Hsu PD, Wright J, Agarwala V, Scott DA \& Zhang F $2013 b$ Genome engineering using the CRISPR-Cas9 system. Nature Protocols 8 2281-2308.

Ren X, Yang Z, Xu J, Sun J, Mao D, Hu Y, Yang SJ, Qiao HH, Wang X, $\mathrm{Hu} \mathrm{Q}$, et al. 2014 Enhanced specificity and efficiency of the CRISPR/ Cas9 system with optimized sgRNA parameters in Drosophila. Cell Reports 9 1151-1162. (doi:10.1016/j.celrep.2014.09.044)

Renaud JB, Boix C, Charpentier M, De Cian A, Cochennec J, DuvernoisBerthet E, Perrouault L, Tesson L, Edouard J, Thinard R, et al. 2016 Improved genome editing efficiency and flexibility using modified oligonucleotides with TALEN and CRISPR-Cas9 nucleases. Cell Reports 14 2263-2272. (doi:10.1016/j.celrep.2016.02.018)

Richardson CD, Ray GJ, DeWitt MA, Curie GL \& Corn JE 2016 Enhancing homology-directed genome editing by catalytically active and inactive CRISPR-Cas9 using asymmetric donor DNA. Nature Biotechnology 34 339-344. (doi:10.1038/nbt.3481)

Richter A, Streubel J \& Boch J 2016 TAL effector DNA-binding principles and specificity. Methods in Molecular Biology 1338 9-25. (doi:10.1007/978-1-4939-2932-0)

Rucker EB 3rd, Dierisseau P, Wagner KU, Garrett L, Wynshaw-Boris A, Flaws JA \& Hennighausen L 2000 Bcl-x and Bax regulate mouse primordial germ cell survival and apoptosis during embryogenesis. Molecular Endocrinology 14 1038-1052.

Sakurai T, Kamiyoshi A, Kawate H, Mori C, Watanabe S, Tanaka M, Uetake R, Sato M \& Shindo T 2016 A non-inheritable maternal Cas9based multiple-gene editing system in mice. Scientific Reports $\mathbf{6}$ 20011. (doi:10.1038/srep20011)

Shen B, Zhang W, Zhang J, Zhou J, Wang J, Chen L, Wang L, Hodgkins A, Iyer V, Huang X, et al. 2014a Efficient genome modification by CRISPR-Cas9 nickase with minimal off-target effects. Nature Methods 11 399-402.

Shen Z, Zhang X, Chai Y, Zhu Z, Yi P, Feng G, Li W \& Ou G $2014 b$ Conditional knockouts generated by engineered CRISPR-Cas9 endonuclease reveal the roles of coronin in C. elegans neural development. Developmental Cell 30 625-636.

Shi Z, Wang F, Cui Y, Liu Z, Guo X, Zhang Y, Deng Y, Zhao H \& Chen Y 2015 Heritable CRISPR/Cas9-mediated targeted integration in Xenopus tropicalis. FASEB Journal 29 4914-4923. (doi:10.1096/fj.15273425)

Shmakov S, Abudayyeh OO, Makarova KS, Wolf YI, Gootenberg JS, Semenova E, Minakhin L, Joung J, Konermann S, Severinov K, et al. 2015 Discovery and functional characterization of diverse class 2 CRISPR-Cas systems. Molecular Cell 60 385-397. (doi:10.1016/j. molcel.2015.10.008) http://jme.endocrinology-journals.org

DOI: 10.1530/JME-15-0305
(๖) 2016 Society for Endocrinology Printed in Great Britain 
Slaymaker IM, Gao L, Zetsche B, Scott DA, Yan WX \& Zhang F 2015 Rationally engineered Cas9 nucleases with improved specificity. Science 351 84-88.

Song Y, Yuan L, Wang Y, Chen M, Deng J, Lv Q, Sui T, Li Z \& Lai L 2016 Efficient dual sgRNA-directed large gene deletion in rabbit with CRISPR/Cas9 system. Cellular and Molecular Life Sciences [in press]. (doi:10.1007/s00018-016-2143-z)

Sternberg SH, Redding S, Jinek M, Greene EC \& Doudna JA 2014 DNA interrogation by the CRISPR RNA-guided endonuclease Cas9. Nature 507 62-67. (doi:10.1038/nature13011)

Stump WT \& Hall KB 1993 SP6 RNA polymerase efficiently synthesizes RNA from short double-stranded DNA templates. Nucleic Acids Research 21 5480-5484. (doi:10.1093/nar/21.23.5480)

Takahashi G, Gurumurthy CB, Wada K, Miura H, Sato M \& Ohtsuka M 2015 GONAD: Genome-editing via Oviductal Nucleic Acids Delivery system: a novel microinjection independent genome engineering method in mice. Scientific Reports 511406. (doi:10.1038/srep11406)

Tanenbaum ME, Gilbert LA, Qi LS, Weissman JS \& Vale RD 2014 A protein-tagging system for signal amplification in gene expression and fluorescence imaging. Cell 159 635-646. (doi:10.1016/j. cell.2014.09.039)

Terns MP \& Terns RM 2011 CRISPR-based adaptive immune systems. Current Opinion in Microbiology 14 321-327. (doi:10.1016/j. mib.2011.03.005)

Thomas KR \& Capecchi MR 1987 Site-directed mutagenesis by gene targeting in mouse embryo-derived stem cells. Cell 51 503-512. (doi:10.1016/0092-8674(87)90646-5)

Tsai SQ, Zheng Z, Nguyen NT, Liebers M, Topkar VV, Thapar V, Wyvekens N, Khayter C, Iafrate AJ, Le LP, et al. 2015 GUIDE-seq enables genome-wide profiling of off-target cleavage by CRISPR-Cas nucleases. Nature Biotechnology 33 187-197.

Varshney GK, Pei W, LaFave MC, Idol J, Xu L, Gallardo V, Carrington B, Bishop K, Jones M, Li M, et al. 2015 High-throughput gene targeting and phenotyping in zebrafish using CRISPR/Cas9. Genome Research 25 1030-1042. (doi:10.1101/gr.186379.114)

Vidigal JA \& Ventura A 2015 Rapid and efficient one-step generation of paired gRNA CRISPR-Cas9 libraries. Nature Communications 68083. (doi:10.1038/ncomms9083)

Wang T, Wei JJ, Sabatini DM \& Lander ES 2014 Genetic screens in human cells using the CRISPR-Cas9 system. Science 343 80-84. (doi:10.1126/science.1246981)

Wang B, Li K, Wang A, Reiser M, Saunders T, Lockey RF \& Wang JW 2015 Highly efficient CRISPR/HDR-mediated knock-in for mouse embryonic stem cells and zygotes. Biotechniques 59 201-208.

Weiss J, Hurley LA, Harris RM, Finlayson C, Tong M, Fisher LA, Moran JL, Beier DR, Mason C \& Jameson JL 2012 ENU mutagenesis in mice identifies candidate genes for hypogonadism. Mammalian Genome 23 346-355. (doi:10.1007/s00335-011-9388-5)

Whitworth KM, Lee K, Benne JA, Beaton BP, Spate LD, Murphy SL, Samuel MS, Mao J, O'Gorman C, Walters EM, et al. 2014 Use of the CRISPR/Cas9 system to produce genetically engineered pigs from in vitro-derived oocytes and embryos. Biology of Reproduction 9178. (doi:10.1095/biolreprod.114.121723)

Williams MR, Fricano-Kugler CJ, Getz SA, Skelton PD, Lee J, Rizzuto CP, Geller JS, Li M \& Luikart BW 2016 A retroviral CRISPR-Cas9 system for cellular autism-associated phenotype discovery in developing neurons. Scientific Reports 6 25611. (doi:10.1038/srep25611)

Wilson TJ \& Kola I 2001 The LoxP/CRE system and genome modification. Methods in Molecular Biology 158 83-94.

Wu X, Scott DA, Kriz AJ, Chiu AC, Hsu PD, Dadon DB, Cheng AW, Trevino AE, Konermann S, Chen S, et al. 2014 Genome-wide binding of the CRISPR endonuclease Cas9 in mammalian cells. Nature Biotechnology 32 670-676. (doi:10.1038/nbt.2889)

Xing HL, Dong L, Wang ZP, Zhang HY, Han CY, Liu B, Wang XC \& Chen QJ 2014 A CRISPR/Cas9 toolkit for multiplex genome editing in plants. BMC Plant Biology 14327

Xue HY, Zhang X, Wang Y, Xiaojie L, Dai WJ \& Xu Y 2016 In vivo gene therapy potentials of CRISPR-Cas9. Gene Therapy [in press]. (doi:10.1038/gt.2016.25)

Yang H, Wang H, Shivalila CS, Cheng AW, Shi L \& Jaenisch R 2013a One-step generation of mice carrying reporter and conditional alleles by CRISPR/Cas-mediated genome engineering. Cell 154 1370-1379.

Yang L, Guell M, Byrne S, Yang JL, De Los Angeles A, Mali P, Aach J, Kim-Kiselak C, Briggs AW, Rios X, et al. 2013b Optimization of scarless human stem cell genome editing. Nucleic Acids Research 41 9049-9061.

Yang H, Wang H \& Jaenisch R 2014 Generating genetically modified mice using CRISPR/Cas-mediated genome engineering. Nature Protocols 9 1956-1968. (doi:10.1038/nprot.2014.134)

Yang L, Guell M, Niu D, George H, Lesha E, Grishin D, Aach J, Shrock E, $\mathrm{Xu} \mathrm{W}$, Poci J, et al. 2015 Genome-wide inactivation of porcine endogenous retroviruses (PERVs). Science 350 1101-1104. (doi:10.1126/science.aad1191)

Yang Y, Wang L, Bell P, McMenamin D, He Z, White J, Yu H, Xu C, Morizono H, Musunuru K, et al. 2016 A dual AAV system enables the Cas9-mediated correction of a metabolic liver disease in newborn mice. Nature Biotechnology 34 334-338. (doi:10.1038/nbt.3469)

Yen ST, Zhang M, Deng JM, Usman SJ, Smith CN, Parker-Thornburg J, Swinton PG, Martin JF \& Behringer RR 2014 Somatic mosaicism and allele complexity induced by CRISPR/Cas9 RNA injections in mouse zygotes. Developmental Biology 393 3-9. (doi:10.1016/ j.ydbio.2014.06.017)

Yoshimi K, Kunihiro Y, Kaneko T, Nagahora H, Voigt B \& Mashimo T 2016 ssODN-mediated knock-in with CRISPR-Cas for large genomic regions in zygotes. Nature Communications 7 10431. (doi:10.1038/ ncomms10431)

Yu Z, Ren M, Wang Z, Zhang B, Rong YS, Jiao R \& Gao G 2013 Highly efficient genome modifications mediated by CRISPR/Cas9 in Drosophila. Genetics 195 289-291. (doi:10.1534/genetics.113.153825)

Yu C, Liu Y, Ma T, Liu K, Xu S, Zhang Y, Liu H, La Russa M, Xie M, Ding S, et al. 2015 Small molecules enhance CRISPR genome editing in pluripotent stem cells. Cell Stem Cell 16 142-147. (doi:10.1016/j. stem.2015.01.003)

Yuan L, Sui T, Chen M, Deng J, Huang Y, Zeng J, Lv Q, Song Y, Li Z \& Lai L 2016 CRISPR/Cas9-mediated GJA8 knockout in rabbits recapitulates human congenital cataracts. Scientific Reports 622024.

Zalatan JG, Lee ME, Almeida R, Gilbert LA, Whitehead EH, La Russa M, Tsai JC, Weissman JS, Dueber JE, Qi LS, et al. 2015 Engineering complex synthetic transcriptional programs with CRISPR RNA scaffolds. Cell 160 339-350. (doi:10.1016/j.cell.2014.11.052)

Zetsche B, Gootenberg JS, Abudayyeh OO, Slaymaker IM, Makarova KS, Essletzbichler P, Volz SE, Joung J, van der Oost J, Regev A, et al. 2015a Cpf1 Is a Single RNA-Guided Endonuclease of a Class 2 CRISPR-Cas System. Cell 163 759-771.

Zetsche B, Volz SE \& Zhang F 2015b A split-Cas9 architecture for inducible genome editing and transcription modulation. Nature Biotechnology 33 139-142.

Zhang L, Jia R, Palange NJ, Satheka AC, Togo J, An Y, Humphrey M, Ban L, Ji Y, Jin H, et al. 2015 Large genomic fragment deletions and insertions in mouse using CRISPR/Cas9. PLOS ONE 10 e0120396.

Zhu X, Xu Y, Yu S, Lu L, Ding M, Cheng J, Song G, Gao X, Yao L, Fan D, et al. 2014 An efficient genotyping method for genomemodified animals and human cells generated with CRISPR/Cas9 system. Scientific Reports 4 6420. (doi:10.1038/srep06420)

Received in final form 3 June 2016

Accepted 7 June 2016

Accepted Preprint published online 7 June 2016

Published by Bioscientifica Ltd 